\title{
Study of the High Temperature Phase of 1,16-Hexadecanediol by Polarized Light Microscopy and Glancing Incidence X-Ray Diffraction
}

M. Ramírez-Cardona ${ }^{1}$, M.P. Falcón-León ${ }^{2}$, G. Luis-Raya ${ }^{2 *}$, G. Mejía-Hernández ${ }^{1}$, R. Arceo ${ }^{3}$, A.I. Martínez-Pérez $^{2}$, G. Villagómez-García ${ }^{2}$ and E. E. Vera-Cardenas ${ }^{4}$.

1. AACTyM, Autonomous University of Hidalgo State, Pachuca, Hidalgo, México.

2. Mechanical Engineering Department, Universidad Politécnica de Pachuca, Pachuca, México.

3. Physics and Mathematics Faculty of Sciences, Universidad Autónoma de Chiapas, Chiapas, México.

4. Mechanical Engineering Department, Instituto Tecnológico de Pachuca, Hidalgo, México.

It has been known for a long time that $\alpha, \omega$-disubstituted linear alkanes displays and odd-even alternation effect in melting points [1-3]. Earlier studies showed higher melting points in compounds with an even number of carbon atoms than those with an odd number of carbon atoms in their skeleton. $\alpha, \omega$-diols disubstituted alkanes exhibit a solid-to-solid phase transition, from 13 atoms in the chain and, for the majority of cases, it is possible to isolate the high temperature phase only in the exothermic process (crystallization). In this work, we present the study of the high temperature phase of the 1,16hexadecanediol (HEDEDOL) using Glancing Incidence X-ray Diffraction (GIXD) and Polarized Light Microscopy (PLM). HEDEDOL sample was purchased from SIGMA-ALDRICH (97\%) and used without further purification. GIXD experiments were performed using a RIGAKU Ultima-IV diffractometer $(40 \mathrm{kV}, 30 \mathrm{~mA})$ with $\mathrm{Cu} \mathrm{K} \alpha_{1,2}\left(\lambda_{1}=1.5406 \AA, \lambda_{2}=1.5443 \AA\right)$ equipped with an Anton Parr HT1500 hot stage camera, and asymmetric configuration was fixed at an incident angle of $5^{\circ}$. GIXD data acquisition was performed at different temperatures in the cooling process from liquid. Transmission optical microscopy observations were performed with an Olympus BX51-P Polarized Light Microscope equipped with a Linkham THMS600 stage. Program DICVOL04 [4] was used to index the reflections with angles smaller than $70^{\circ} 2 \theta$ of the high-temperature (i.e. $88^{\circ} \mathrm{C}$ ) GIXD pattern, and the results showed an orthorhombic cell with space group $P \mathrm{~mm} 2$ as the most reliable solution. The LeBail's method [5] was used in the subsequent whole-pattern fitting process via the "Profile Matching" option implemented into the FULLPROF program [6]. Unit-cell parameters, FWHM's coefficients, as well as peak-shape parameters were refined. The background was determined by linear interpolation of 43 manually selected points using the graphical interface of program WinPlotr [7]. The "Profile Matching" procedure resulted in reasonably values for the $\mathrm{R}$ factors $\left(\mathrm{R}_{\mathrm{wp}}\right.$ and $\left.\mathrm{R}_{\mathrm{p}} \leq 2.0 \%\right)$. Final cell parameters obtained were: $a=11.832(1) \AA, b=10.933(5) \AA, c=8.471(6) \AA$.

It can be observed from Figure 1 the evolution of HEDEDOL diffraction patterns at different temperatures on cooling process taken from the melt, this sugest the presence of two phases at different temperatures. Profile Matching performed on HEDEDOL at $88^{\circ} \mathrm{C}$ is shown in Figure 2, while the PLM images at crossed nicols at $35^{\circ} \mathrm{C}$ can be seen in Figure $3 \mathrm{a}$ and high temperature phase $\left(88^{\circ} \mathrm{C}\right)$ can be observed in Figure $3 \mathrm{~b}$ from which long acicular morphology of crystals is clearly visible.

\section{References}

[1] Y. Ogawa, N. Nakamura. Bull. Chem. Soc. Jpn. 72 (1999), 943-946.

[2] V. R. Thalladi, R. Boese, H. C. Weiss. Angew. Chem. Int. Ed. 39 (2000), 918-922.

[3] V.R. Thalladi, M. Nüsse, R. Boese. J. Am. Chem. Soc. 122 (2000), 9227-9236.

[4] A. Boultif, , D. Louër, J. Appl. Cryst. 37 (2004), 724-731. 
[5] A. Le Bail, H. Duroy, J. L. Fourquet. Mater. Res. Bull. 23 (1988), 447-452.

[6] J. Rodriguez-Carvajal. XV Congress of the IUCr, Toulouse, France; 1990.

[7] T. Roisnel, J. Rodriguez-Carvajal. European Powder Diffraction EPDIC 7, Barcelona, Spain; 2001.

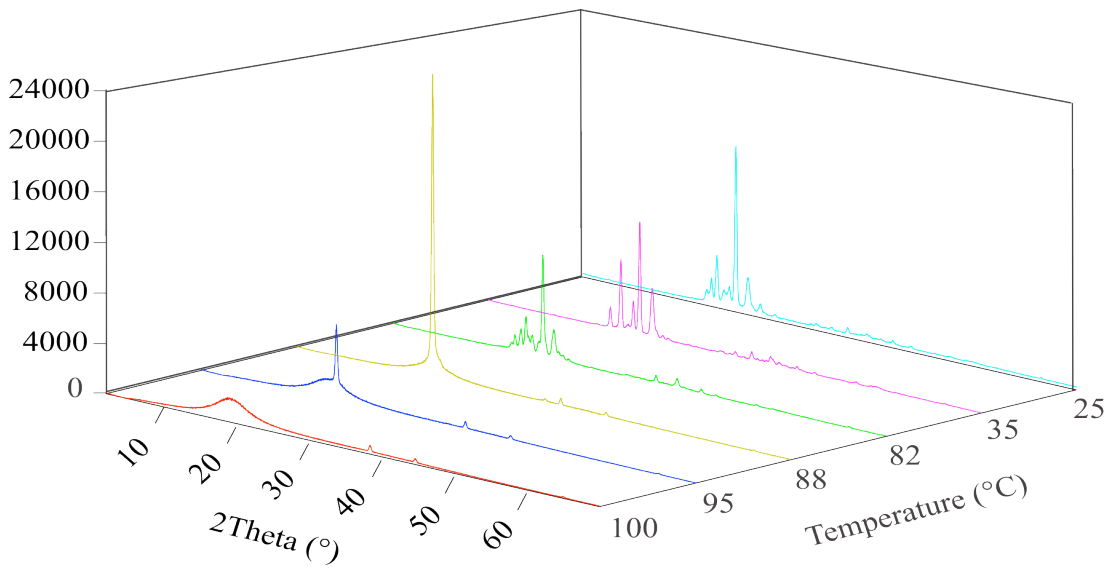

Figure 1. GIXD patterns of HEDEDOL sample showing the evolution of high to low temperature phases from liquid.

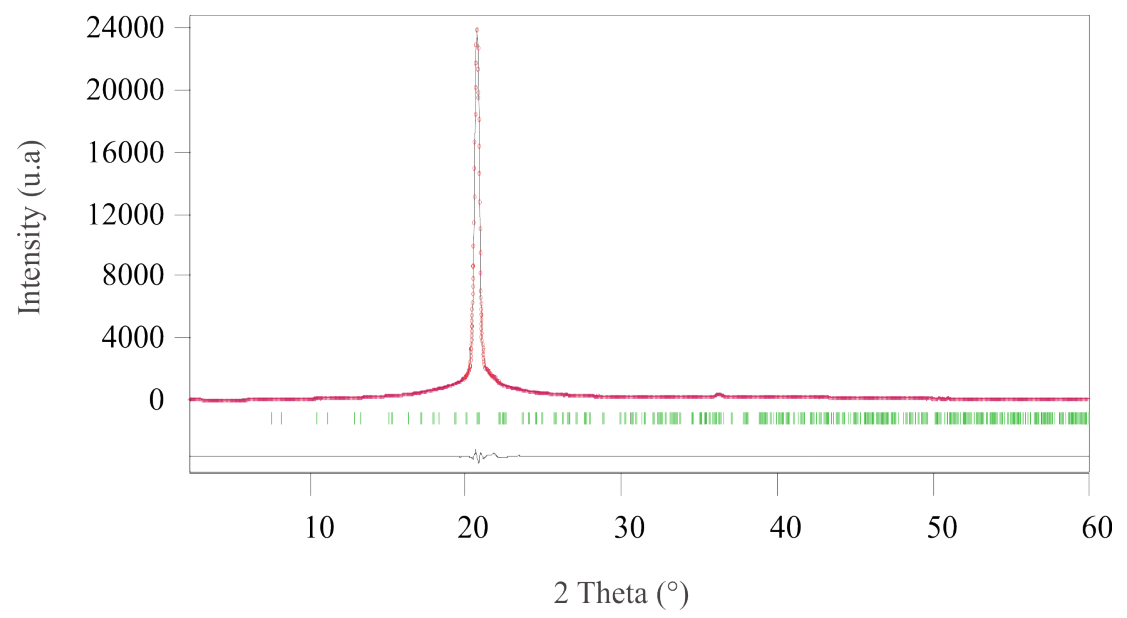

Figure 2. Profile Matching of HEDEDOL sample taken from GIXD experiment at $88^{\circ} \mathrm{C}$.
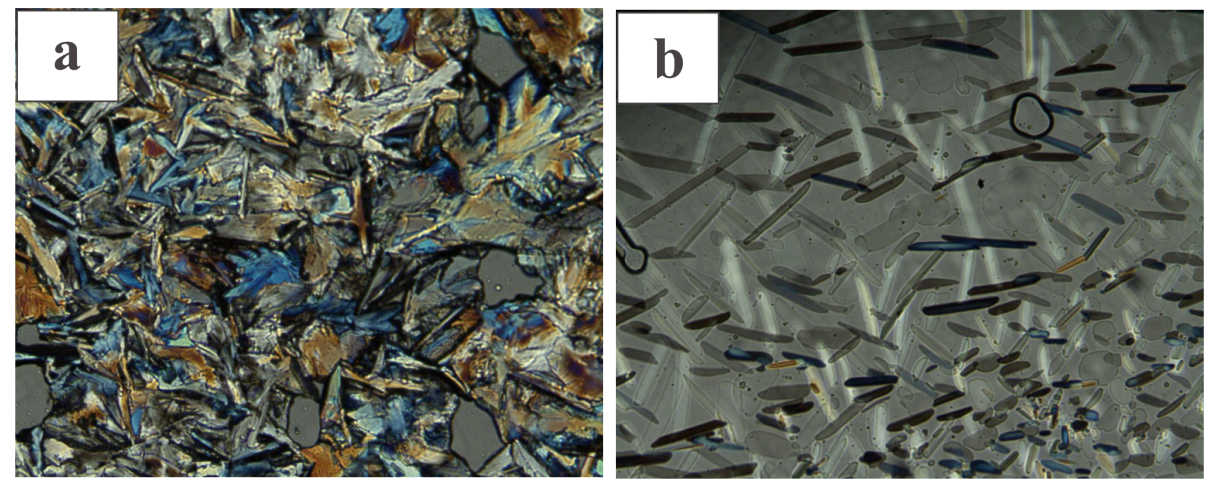

Figure 3. PLM images of HEDEDOL taken with a magnification of $100 \mathrm{X}$ at: a) $35^{\circ} \mathrm{C}$ in the lowtemperature phase and b) $88^{\circ} \mathrm{C}$ in the high-temperature phase. 